\title{
$\left[{ }^{68} \mathrm{Ga}\right]$ Ga-tilmanocept PET/CT lymphoscintigraphy for sentinel lymph node detection in early-stage oral cavity carcinoma
}

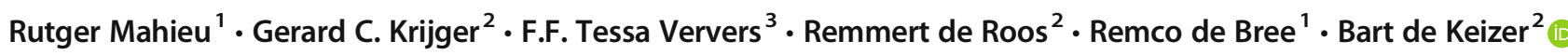

Received: 24 August 2020 / Accepted: 29 September 2020 / Published online: 13 November 2020

(C) The Author(s) 2020

The sentinel lymph node (SLN) procedure is routinely performed for nodal staging in several malignancies, including early-stage oral cancer. In oral cancer, the SLN imaging procedure usually consists of peritumoral injections with a $\left[{ }^{99 \mathrm{~m}} \mathrm{Tc}\right] \mathrm{Tc}$-labelled radiotracer followed by dynamic and planar lymphoscintigraphy and SPECT/ CT $[1,2]$. A frequently discussed limitation of this procedure in oral cancer arises in situations where SLNs are located in close vicinity of the radiotracer injection site. Due to the limited resolution of conventional scintigraphy and SPECT/CT, injection site activity can hide adjacent SLNs and hamper discrimination between injection site and SLNs (shine-through phenomenon), potentially resulting in false-negative SLN procedure outcomes $[3,4]$. PET/CT lymphoscintigraphy may offer a solution, as it provides superior spatial resolution compared with conventional scintigraphy and SPECT/CT $[4$, 5]. Here, we present the first within-patient comparison between PET/CT lymphoscintigraphy using $\left[{ }^{68} \mathrm{Ga}\right] \mathrm{Ga}-$ tilmanocept (10 MBq; $15 \mathrm{~min}$ post-injection) and SPECT/CT with $\left[{ }^{99 \mathrm{~m}} \mathrm{Tc}\right] \mathrm{Tc}$-tilmanocept $(74 \mathrm{MBq} ; 2 \mathrm{~h}$ post-injection) in a cT1N0 tongue cancer patient, both acquired on the day before surgery. Maximum intensity projection images (MIP) of PET (D) demonstrate its superior resolution compared with SPECT $(H)$. Furthermore, two separate lymph vessels can be identified on PET/CT lymphoscintigraphy (D), which are not visualized on SPECT/CT (H). Also note that the activity in a SLN in level $\mathrm{Ib}$ on the right site is better visible on axial (A), sagittal (B), and coronal (C) PET/CT lymphoscintigraphic images compared with corresponding SPECT/CT reconstructions (E,F,G). Surgically, five SLNs were localized and harvested (level $\mathrm{Ib}, 3 \mathrm{x}$ level IIa and level III), using a conventional gammaprobe. Histopathological assessment showed metastasis in one SLN located in level IIa. Complementary neck dissection of level I-IV showed no additional lymphatic metastasis (Figure 1).
This article is part of the Topical Collection on Oncology - Head and Neck.

Bart de Keizer

b.dekeizer@umcutrecht.nl

1 Department of Head and Neck Surgical Oncology, University Medical Center Utrecht, Utrecht, the Netherlands

2 Department of Radiology and Nuclear Medicine, University Medical Center Utrecht, Heidelberglaan 100, 3584, CX Utrecht, the Netherlands

3 Department of Pharmacy, University Medical Center Utrecht, Utrecht, the Netherlands 


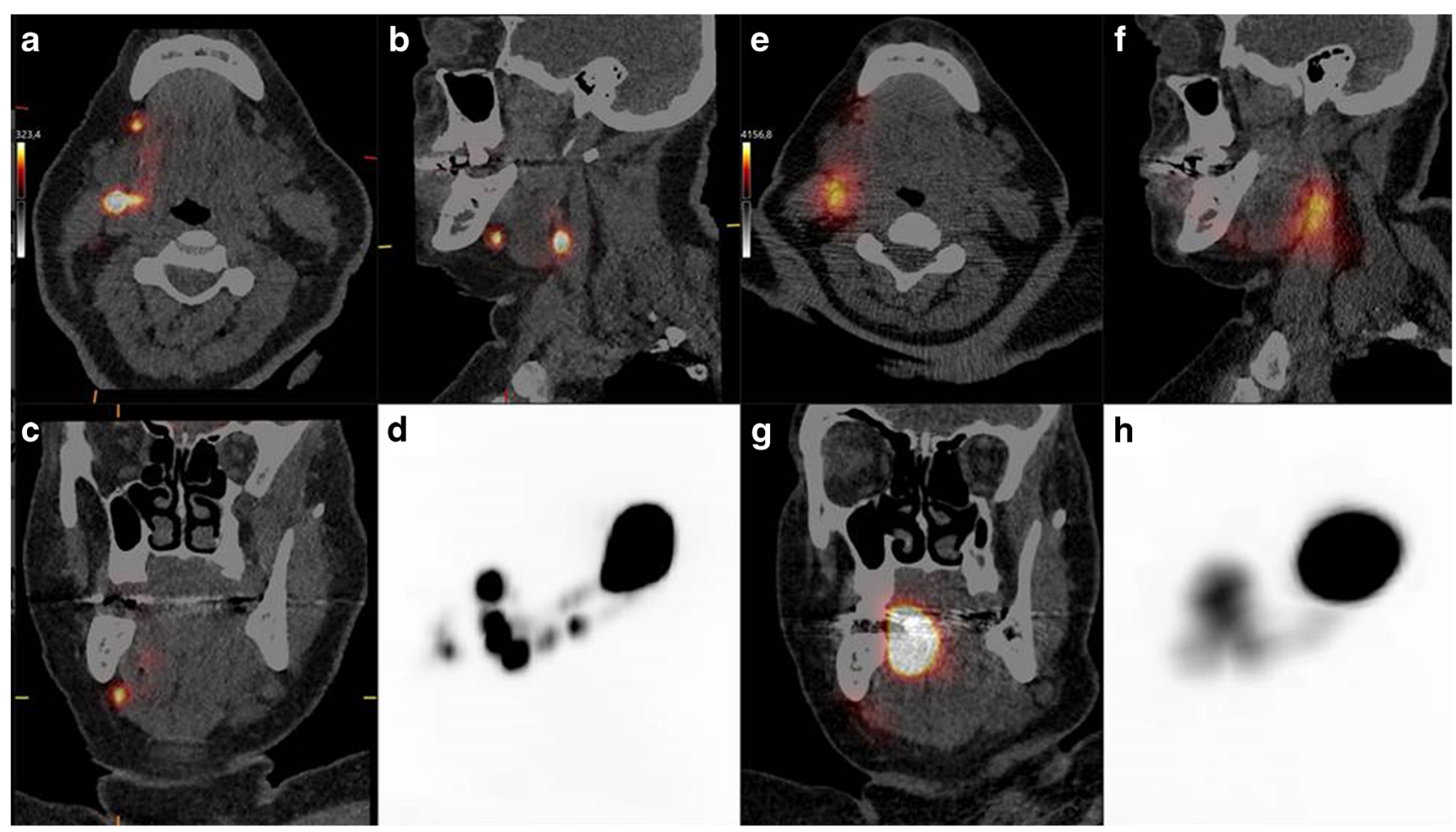

Figure $1 \mathrm{P}\left[{ }^{68} \mathrm{Ga}\right] \mathrm{Ga}$-tilmanocept PET/CT vs. $\left[{ }^{99 \mathrm{~m}} \mathrm{Tc}\right] \mathrm{Tc}$-tilmanocept PET/CT.

Funding Open access funding provided by University Medical Center Utrecht.

\section{Compliance with ethical standards}

Conflict of interest The authors declare that they have no conflicts of interest. All procedures performed in studies involving human participants were in accordance with the ethical standards of the institutional and/or national research committee and with the 1964 Helsinki declaration and its later amendments or comparable ethical standards. This study was approved by the medical ethical review board of the University Medical Center Utrecht (NL71558.041.19). Informed consent was obtained from the participant included in this study.

Open Access This article is licensed under a Creative Commons Attribution 4.0 International License, which permits use, sharing, adaptation, distribution and reproduction in any medium or format, as long as you give appropriate credit to the original author(s) and the source, provide a link to the Creative Commons licence, and indicate if changes were made. The images or other third party material in this article are included in the article's Creative Commons licence, unless indicated otherwise in a credit line to the material. If material is not included in the article's Creative Commons licence and your intended use is not permitted by statutory regulation or exceeds the permitted use, you will need to obtain permission directly from the copyright holder. To view a copy of this licence, visit http://creativecommons.org/licenses/by/4.0/.

\section{References}

1. Liu M, Wang SJ, Yang X, Peng H. Diagnostic efficacy of sentinel lymph node biopsy in early oral squamous cell carcinoma: a metaanalysis of 66 Studies. PLoS One. 2017;12(1):e0170322.

2. Giammarile F, Schilling C, Gnanasegaran G, Bal C, Oyen WJG, Rubello D, et al. The EANM practical guidelines for sentinel lymph node localisation in oral cavity squamous cell carcinoma. Eur J Nucl Med Mol Imaging. 2019 Mar;46(3):623-37. https://doi.org/10.1007/ s00259-018-4235-5.

3. Den Toom IJ, Boeve K, Lobeek D, Bloemena E, Donswijk ML, de Keizer B, et al. Elective neck dissection or sentinel lymph node biopsy in early stage oral cavity cancer patients: the Dutch experience. Cancers. 2020;12:1783. https://doi.org/10.3390/ cancers 12071783.

4. Heuveling DA, van Schie A, Vugts DJ, Hendrikse NH, Yaqub M, Hoekstra OS, et al. Pilot study on the feasibility of PET/CT lymphoscintigraphy with $89 \mathrm{Zr}$-nanocolloidal albumin for sentinel node identification in oral cancer patients. J Nucl Med. 2013;54(4): 585-9. https://doi.org/10.2967/jnumed.112.115188.

5. Rahmim A, Zaidi H. PET versus SPECT: strengths, limitations and challenges. Nucl Med Commun. 2008;29(3):193-207. https://doi. org/10.1097/MNM.0b013e3282f3a515.

Publisher's note Springer Nature remains neutral with regard to jurisdictional claims in published maps and institutional affiliations. 